
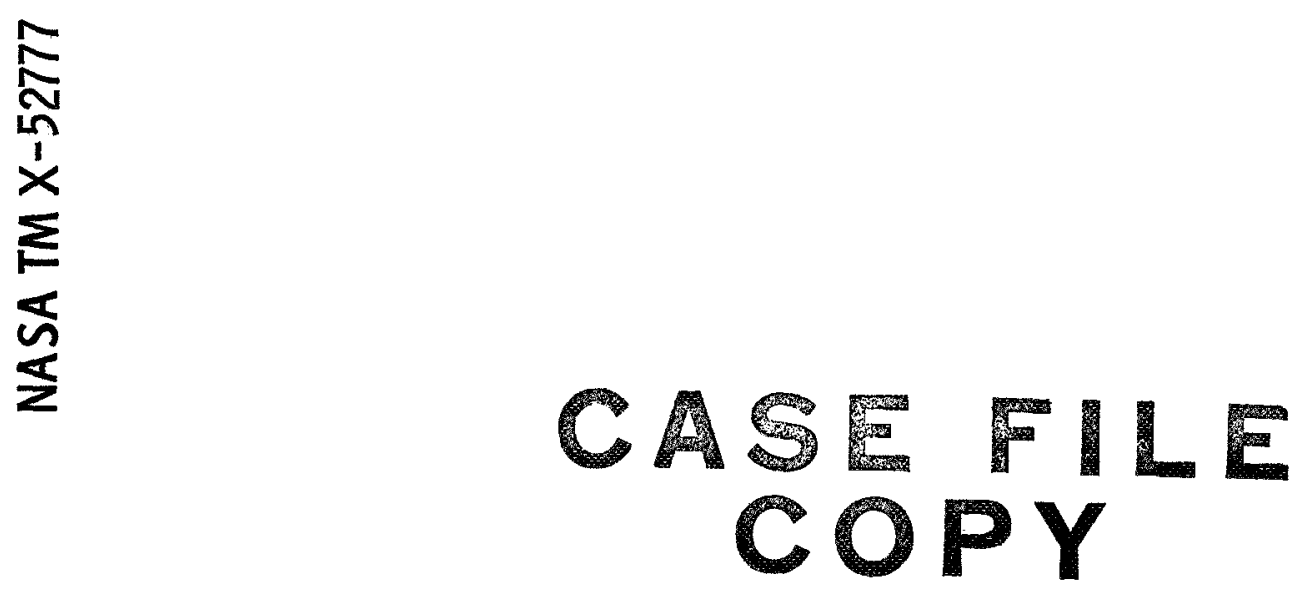

\title{
DESIGN CONCEPTS FOR FIBER-METAL MATRIX COMPOSITES BOR ADVANCED GAS TURBINE BLADES
}

by John W. Weeton

Lewis Research Center

Cleveland, Ohio

TECHNICAL PAPER proposed for presentation at Fifteenth Annual International Gas Turbine Conference and Products Show sponsored by the American Society of Mechanical Engineers Palais du Centanaire, Brussels, Belgium, May 24-28, 1970 
DESIGN CONCEPTS FOR FIBER-METAL MATRIX COMPOSITES

FOR ADVANCED GAS TURBINE BLADES

by John W. Weeton

Lewis Research Center

Cleveland, Ohio

TECHNICAL PAPER proposed for presentation at

Fifteenth Annual International Gas Turbine Conference and Products

Show sponsored by the American Society of Mechanical Engineers

Palais du Centanaire, Brussels, Belgium, May 24-28, 1970

NATIONAL AERONAUTICS AND SPACE ADMINISTRATION 


\section{DESIGN CONCEPTS FOR FIBER-METAL MATRIX COMPOSITES}

FOR ADVANCED GAS TURBINE BLADES

by John W. Weeton

Lewis Research Center

National Aeronautics and Space Administration

Cleveland, Ohio

\section{ABSTRACT}

Advances in gas turioine technology depend in large measure upon advances in materials technology. Arbitrary stringent criteria for room temperature specific strengths and moduli and for $2000^{\circ} \mathrm{F}, 1000$-hour stress-rupture strength were chosen for design goals. Required fiber properties to meet these criteria were calculated for fiber and matrix material combinations of widely ranging densities. It was demonstrated, on a first approximation basis, that numerous composite materials with specific tensile or stress-rupture strengths and with specific moduli superior to those of conventional materials 'can be "designed"? from fiber and matrix" materials availabìe today.

\section{INTRODUCTION}

Advances in gas turbine technology depend in large measure upon advances possible in materials technology. The type of material required for each component of the engine varies with the application or mission of the engine. Generally, engines with increased thrust per pound are desired. Some engines, particularly those for commercial applications, require greater economy and longer life of the components. Military aircraft, too, hawe different engine requirements depending on their mission. For example, a fighter aircraft would require a different engine from that of a 
long range bomber. Engines for high velocity aircraft, those for use between Mach 1.5 to 3 would not require afan, whereas engines for the high subsonic to transonic speed of Mach 0.7 to 1.5 would probably have a fan (ref, 1)。 $;$ Air -.. craft for the VTOL and VSTOL applications would require high thrust lightweight turbofan engines.

Although materials requirements for specific components of the many different types of engines will obviously vary considerably, there are some general material property requirements that are apropos to almost all engines. The schematic illustration of Fig. 1 shows the vital components of a hypothetical turbojet engine containing most of the components of all engines previously mentioned. Those components of the engine that are acted upon by the principal dynamic forces are identified. Some of the components such as vanes, the disc, and the combustion chambers are acted upon by fluctuating temperatures, pressures, or gas impingement and thereby may be affected by mechanical fatigue, thermal fatigue, erosion oxidation, and corrosion. Others must withstand centrifugal stresses and high temperatures as well。 They include the turbine blades and the compressor blades. Fan blades must also withstand high centrifugal stresses but at temperatures ranging from ambient to possibly $500^{\circ} \mathrm{F}$.

This paper will be concerned with the potential use of composite materials for the fan, the compressor blades, and the hot or first stage turbine blades. The objectives will be to show that materials with significant improvements in the parameters, specific strengths, moduli of elasticity, and specific stress-rupture strength can be "designed" from existing fiber and matrix materials of widely differing densities. The significance of the results, in relation to materials available; will be discussed. 
For low temperature applications, specific strengths and moduli will be specified for hypothetical advanced composite materials。Calculated fiber tensile strengths and moduli necessary to achieve the design criteria will be presented. Room temperature $\left(72^{\circ} \mathrm{F}\right)$ tensile properties will be used for the examples. For high temperature applications, a specific stress-to-rupture strength criterion will be specified for composites, and the fiber stressrupture strengths necessary to achieve this will be calculated。

For both of the above examples, tabulations of the fibers capable of meeting the design criteria will be presented along with a discussion of other factors affecting the choice of materials to meet the criteria specified.

\section{DESIGN CONCEPTS}

\section{Fundamentals - Strengthening Mechanisms}

The fundamental concepts relative to the strengthening of composites must be kept in mind or a composite material cannot be successfully constructed. For a fiber to reinforce a metal matrix, for example, there must be quantities of fibers greater than a critical volume percent if the material is to be strengthened above the initial strength of the matrix material.(refs. 2 and 3). If short length fibers are to be utilized, the fiber must have a critical length to diameter ratio sufficient to permit it to transmit its full strength to the matrix by a shear process. In fact, the actual length of the fibers embedded in a composite must be considerably greater than the critical length if it is desired to obtain essentially the equivalent of the full strength of the fiber or the equivalent of a full length fiber embedded in a material (refs. 2 to 4 ).

The alinement of fibers in a composite relative to the direction of load is also most important. The composite can fail by shear of the matrix if a 
"critical angle" of misalinement is exceeded. This angle can be a very few degrees depending on the matrix strength, fiber volume percent, and composite strength (assuming perfect alinement)(refs. 2, 3, and 5)。Because the shear strengths of metal matrices are smaller at elevated temperatures, the critical angles are smaller also. There are ways to compensate for the offangles problems and to design composites with controlled cross-orientations. The ply technique has been very successfully used by Rolls-Royce, for example, to produce compressor blades of glass or graphite in plastic (refs. 6 and 7 , respectively). Cross plying and the resultant changes in properties with variations in plies will not be discussed as a part of this paper. Another mechanical factor that must be considered is strengthening the matrix by triaxial or biaxial restraints or by diminishing the interfiber distances (refs. 2 and 8). Fibers which are closely packed effectively restrain the matrix which, in turn, causes the composite to be strengthened and at times embrittled.

From a metallurgical standpoint there are many factors aside from strength or properties of the individual constituents which must be taken into account when making a composite. Metallurgical compatibility is a prime consideration. Ideally, fibers that would not react with a matrix would be excellent for a composite. Unfortunately, only a limited number of fiber-metal systems are nonreactive or mutually insoluble. Work with mutually insoluble materials as model systems studies has been accomplished by several investigators. Some of the first work that has been done to study the stress, strain, and tensile relations as wells as the stress-rupture relations of mutually insoluble model system materials is given in Refs。9 and 10. In Ref.9, rule of mixture relations were shown to represent the behavior of mutually insoluble fiber-metal matrix composites under room 
temperature tensile conditions. Similarly, the same relationship was found to represent materials tested in elevated temperature tension tests. Somewhat modified equations were written for both stress-rupture and creep conditions in Ref. 10. These equations for both tensile and stress-rupture behavior and the nomenclature used for them are given below because they are used as : the base line for the prediction or calculation of properties that will be obtained in this paper.

Tensile conditions (ref。9)

$$
\begin{aligned}
& \sigma_{\mathrm{c}}=\sigma_{\mathrm{f}} \mathrm{V}_{\mathrm{f}}+\sigma_{\mathrm{m}}^{*} \mathrm{~V}_{\mathrm{m}} \\
& \mathrm{E}_{\mathrm{c}}=\mathrm{E}_{\mathrm{f}} \mathrm{V}_{\mathrm{f}}+\mathrm{E}_{\mathrm{m}} \mathrm{V}_{\mathrm{m}}
\end{aligned}
$$

Stress rupture (ref. 10)

$$
\left(\sigma_{\mathrm{c}}\right)_{\mathrm{t}}=\left[\left(\sigma_{\mathrm{f}}\right)_{\mathrm{t}} \mathrm{v}_{\mathrm{f}}+\left(\sigma_{\mathrm{m}}\right)_{\mathrm{t}} \mathrm{v}_{\mathrm{m}}\right]_{\mathrm{t}=\mathrm{constant}}
$$

where

$\sigma \quad$ ultimate tensile strength for Eq. (1) or stress-rupture strength for given time and temperature for $\mathrm{Eq}$. (3)

$\sigma_{\mathrm{m}}^{*} \quad$ stress on matrix taken from stress-strain diagram at strain equivalent to that for the ultimate tensile strength of fiber

V volume fraction of constituent

E: modulus of elasticity

c composite

f fiber

m matrix

$\mathrm{t}$ time

Other analytical studies have been made some of which are far more complex than those indicated. These are associated with elastic-plastic and 
elastic-elastic deformations of composites, the statistics of the fiber failures within the composite and other factors. A summary of available theories of fiber composites is given in Ref. 11 where some additional semiemperical theories are also proposed.

General Approach for Design of Composite Materials

This section is devoted to the design of materials rather than the design of structures. Materials will be designed from the viewpoint of a metallurgist or materials engineer rather than from a stress analysis viewpoint. Because the fiber-metal matrix field has been in the state of evolution, the usual approach to the development of fiber composites has been to determine whether a fiber of a given material could be combined with a desired matrix into an integral composite by one or more methods. Where possible the investigator would compare the mechanical properties of the composite with rule-of mixtures values calculated from known strengths or moduli of fibers and matrix. Otherwise, strengths obtained were compared with those of competitive materials or materials that the composite would possibly replace. Experiments involving the combining of various types of fibers with various matrices have been conducted in large numbers. Many of the fiber materials used reacted deleteriously with the matrices and resultant composites were weak. In numerous cases, where reactions were controllable or minor, composites were found to have excellent strengths. Generally, there was a tendency to experiment with lightweight fiber materials even when the material could be expected to react with the matrix. Properties achieved with composites were not enough, however, to insure the use of a given combination of materials because better and better fibers were evolving as a result of fiber research and development efforts. This state of flux tended to prevent manufacturers 
from designing and producing materials to meet specific needs. Cost of both fibers and fabrication of composites also tend to limit the application of actual hardware.

The approach to be described will include: (1) arbitrarily picking, as design goals or criteria for composite materials, specific strengths, or moduli that would be significantly above those of presently used fan or compressor and turbine blade materials; (2) calculating fiber properties that would be necessary to achieve the desired composite properties for a wide range of fiber and matrix densities; (3) determining from available fiber data, what fibers could meet the design criteria, analyzing, to some degree fiber limitations and possible future fiber developments; and (4) comparing some of the best composite material properties available with the design criteria and with competitive compressor and turbine material data.

The various equations previously presented can be used to design; on a first approximation basis, a desired composite. The designer of a composite has seven principal variables to contend with: the strength of the fiber (or the modulus), the strength (or modulus) of the matrix, the density of the fiber, the density of the matrix and the volume fraction of the fiber. It should be obvious that higher strength fibers tend to make higher strength com posites, that lower density fibers make lower density composites and that high fiber volume percent composites usually would be stronger than low volume percent composites. However, it is believed that the magnitude of interrelated effects of the seven parameters will be far better appreciated with the examples that will be given. 
FIBER PROPERTIES FOR ROOM TEMPERATURE COMPOSITES Fiber Strength Requirements

Most gas turbines in the United States use titanium alloy blades such as $\mathrm{Ti}-6 \mathrm{Al}-\mathrm{V}$ for the fans or low pressure compressor stages. This alloy is forged and heat treated which gives it an ultimate strength of approximately 140000 to 150000 psi and enough toughness for use as compressor blades. Strong aluminum, steel, and some superalloys have been used or are in use for some stages of some compressors. The stainless steel and superalloy materials have their greatest potential for high temperature compressor blades. Some typical properties of these types of alloys in their highest strength form for bulk structural materials are shown in table I. Materials for the compressors are fabricated or heat treated to yield lower than maximum stress levels. The reason is that in their highest strength form they are often too brittle. In the strongest conditions their strength-to-density ratios (specific strengths) either approximate or exceed $1 \times 10^{6}$ inches. In all cases their modulus-to-density ratios (specific modulus) are slightly over $100 \times 10^{6}$ inches. The Ti-6Al-4V alloy mentioned initially has a specific strength of about 860000 inches and a specific modulus of $103 \times 10^{6}$ inches.

For this paper, a specific strength of $1.5 \times 10^{6}$ inches and a specific modulus of $167 \times 10^{6}$ inches arbitrarily will be considered the ${ }^{8}$ design criteria" for the materials of interest. These values would represent materials with significant improvements in specific strengths and moduli of 50 and 67 percent, respectively, relative to those of the best bulk structural materials presently in use. If materials with the arbitrarily selected design param eters were produced, blades could operate with greater tip speeds. Other benefits, such as enhanced fatigue and impact resistance would probably accrue as well. 
Materials then, with strength to density ratios of $1.5 \times 10^{6}$ inches, would represent a 50 percent increase in the specific strength of the strongest materials and even more of an increase relative to the titanium alloy value noted. Such materials would have applications for both fans and compressor blades. Similarly, if a material with a two-thirds increase in modulus to density ratio could be produced, it, too, would be of great interest for use in gas turbines. It will be assumed that rule-of-mixture strengths are attainable with different materials. Dividing the rule-of-mixtures equation for strengths (eq. (1)) or moduli (eq. (2)) by the rule-of-mixtures equation for density the following equations can be obtained:

$$
\begin{aligned}
& \sigma_{f}=\frac{1}{V_{f}}\left(S_{D} \rho_{m}-\sigma_{m}^{*}\right)+S_{D}\left(\rho_{f}-\rho_{m}\right)+\sigma_{m}^{*} \\
& E_{f}=\frac{1}{V_{f}}\left(E_{D} \rho_{m}-E_{m}\right)+E_{D}\left(\rho_{f}-\rho_{m}\right)+E_{m}
\end{aligned}
$$

where:

$\sigma_{f} \quad$ is the strength of a fiber (psi) necessary to give the composite a "design" strength-to-density ratio (specific strength) - 1500000 inches for this paper.

$\sigma_{\mathrm{m}}^{*}$ the stress in the matrix at the strain level (elongation) of the fiber at which the ultimate strength of the fiber is achieved (psi).

$\rho \quad$ density. $\left(1 \mathrm{~b} /\right.$ in. $\left.^{3}\right)$

$\mathrm{S}_{\mathrm{D}} \quad$ design specific strength

$\mathrm{V}_{\mathrm{f}} \quad$ volume fraction fiber in composite

$\mathrm{f}, \mathrm{m}$, subscripts for fiber and matrix 
$\mathrm{E}_{\mathrm{m}} \quad$ modulus of elasticity of matrix (psi)

$\mathrm{E}_{\mathrm{f}}$ modulus of elasticity of fiber (psi) necessary to give composite a "design" modulus-to-density ratio (specific modulus) $-167 \times 10^{6}$ inches for this paper

$\mathrm{E}_{\mathrm{D}}$ design specific modulus (inches)

Since these linear equations permit the calculation of the fiber strength or modulus necessary to give a composite the desired specific strength and moduli, these values may be plotted as is shown in Figs. 2 and 3. The calculated curves were determined for nine combinations of materials; fibers of three different densities, and matrices of three different densities. Table II shows samples of the types of matrices that would have densities similar to those of the examples. In addition it shows the strength and moduli values that typify materials of different densities that were used to calculate the values for the curves. Note that the "strength" used for $\sigma_{m}^{*}$ are less than the strengths of comparable materials indicated in Table $I$.

Each set of curves, one for each fiber of a given density, converges at an apex at 100 percent fibers. The apex value may be calculated using equations(4) and(5). or more simply by multiplying the design specific strength or specific modulus of the composite by the density of the fiber. With rectangular, square, or hexangonal shapes it would be theoretically possible to produce a material made from 100 percent fibers. In a sense it would be a composite. On the other hand, since most small diameter filaments are circular in cross section, the maximum theoretical packing of fibers would be about 90 percent for such materials. It is very difficult to pack large volume percentages of fibers (either filaments or whiskers) in a given cross section. The largest value achieved at the Lewis Research Center has been to pack 80 percent by volume. At present, a usual working practical limit is about 70 percent. 
Considering first Fig. 2, some of the general trends are that, as the volume percent of fibers of the composite is increased, the required fiber strength to achieve the "design" criterion for specific strength becomes less. Conversely, decreasing the volume of fibers also requires very large increases in fiber strengths. Also for a given fiber of specific density, increasing the matrix density requires fibers of greater and greater strength to achieve the design criteria. Note that the slopes of the curves increase rapidly with increasing matrix density.

The curves show very graphically that, for a given weight of matrix, heavier fibers must be far stronger than lighter fibers to achieve the design criterion. Thus a fiber with $0.3 \mathrm{lb} / \mathrm{in}^{3}$ density must be 300000 psi stronger than a fiber with $0.1 \mathrm{lb} / \mathrm{in}^{3}{ }^{3}$ density, or a fiber with $0.6 \mathrm{lb} / \mathrm{in}^{3}{ }^{3}$ must be $450000 \mathrm{psi}$ stronger than a $0.3 \mathrm{lb} / \mathrm{in}^{3}$ fiber or 750000 psi stronger than a $0.1 \mathrm{lb} / \mathrm{in}^{3}$ fiber. These are impressively large differences in strength requirements. Of course, these values would be less if a lower design specific strength had been chosen. The curves of Fig. 2 certainly would give the designer an incentive to use a lightweight fiber wherever possible. On the other hand, he might prefer to select his materials on the basis of compatibility with the matrix, corrosion resistance of the matrix, or other unique properties. Other factors such as cost and availability of the fiber must be considered. Lower grade fibers of a given type might be weaker than optimum values and yet strong enough to meet the design criterion. These, too, should be less expensive than optimizedproperty fibers. Table III, a compilation of many of the available fibers, is presented to permit comparison or selection of fiber materials that can satisfy the design criteria mentioned previously. This table (ref.12) has been 
modified by the author to up-date both properties and costs. Actually, the values may change from day to day.

Since many of the practical composites of interest today are made to contain approximately 50 volume percent $(\mathrm{v} / \mathrm{o})$ filaments and since lower fiber content composites for both filament and whisker composites are of interest, a table extracting some of the data from Fig. 2 is presented in Table IV. Shown are calculated fiber strengths needed for 20 and $50 \mathrm{v} / 0$ fiber composites to satisfy the specific strength criterion of $1.5 \times 10^{6}$ inches. The presently available fibers with adequate or more than adequate strengths to produce such composites are given also. The fibers selected or indicated to have the strength necessary for the composite of interest were selected using the data of Table III. In some cases possible future fibers are indicated in footnotes in the table.

A low density matrix material such as aluminum would require only relatively weak (275 000 psi fibers), low density fibers for a $50 \mathrm{v} / 0$ composite. From Table III it may be seen that at least 5 types of whiskers and 12 filamentary materials could be used to achieve the design criterion. These would include alumina $\left(\mathrm{Al}_{2} \mathrm{O}_{3}\right)$ (which is slightly more dense than $0.1 \mathrm{lb} / \mathrm{in} .{ }^{3}$ ), beryllium oxide $(\mathrm{BeO})$, boron carbide $\left(\mathrm{B}_{4} \mathrm{C}\right)$, silicon carbide $(\mathrm{SiC})$, silicon nitride $\left(\mathrm{Si}_{3} \mathrm{~N}_{4}\right)$ and graphite. Of these, the two types of whiskers that have been produced and studied to the greatest degree are $\mathrm{Al}_{2} \mathrm{O}_{3}$ and $\mathrm{SiC}$. The latter are even being made in quantities large enough to be considered commercial, prices for SiC being as low as $\$ 100.00$ per pound. In fact, if the predicted costs for SiC are ultimately achieved, namely costs of $\$ 10.00$ per pound ( $\$ 1.20$ per cubic inch), the materials could be less expensive than many other matrix materiais. $\mathrm{Al}_{2} \mathrm{O}_{3}$ : although expensive can be purchased in quantities large enough to experiment 
with, and in selected sizes and quality. The manufacturers of all of the whiskers would most certainly be pleased to receive large orders for the dif ferent whiskers, even though it would take time to supply large quantities to a purchaser. In general, most whiskers are still considered experimental fibers and some, in reality, are laboratory products only.

Of the numerous filaments that could be used to fabricate lightweight matrix composites with the desired properties $\left(1.5 \times 10^{6}\right.$ in. specific strength and $167 \times 10^{6}$ in. specific modulus), the ones that could be considered commercial, in the sense that they can be obtained readily in modest to large quantities, are the glasses, graphite, B, SiC coated B, SiC, possibly boron nitride (BN) and monocrystal $\mathrm{Al}_{2} \mathrm{O}_{3}$. Some of the other fibers, although made successfully in some cases are experimental materials rather than commercial ones. Another newer type that can be purchased and that has approximately the density of $0.1 \mathrm{lb} / \mathrm{in}^{3}{ }^{3}$ is monocrystalline alumina fibers made from liquid melts.

It is readily apparent from table IV that there are fewer choices of fibers available to meet the design specific strength desired for $20 \mathrm{v} / \mathrm{o}$ composites than for the $50 \mathrm{v} / 0$ composites. In addition, even with the low density fibers, and there are more types of these than heavier fibers, the strength requirements become so great, as the matrix weight goes up, that whiskers have to be considered as the only possible materials than can be used to achieve the types of composite specific strengths called for by the design criterion. With whiskers there are many considerations to be kept in mind, not the least of which are the problems posed by the scatter in properties of whiskers and the difficulty in handling them. Generally, it is easier to produce whisker com- 
posites with less than about $25 \mathrm{v} / \mathrm{o}$ whiskers. By far most whisker composites made to date have volume percents lower than this value. Whiskers as they are usually grown not only have variations in length, diameter, and quality but have the intrinsic property variations that go with these variables. Thus to have average values in strength above $2 \times 10^{6}$ psi, (for example) requires a separation of high quality whiskers from the general production batches produced and specialized handling techniques to prevent damage to them. Every strength shown in Table IV is possible to achieve with whiskers but to date the higher strength whiskers would be difficult to obtain in large quantities.

As the density of the fibers is increased to either 0.3 or $0.6 \mathrm{lb} / \mathrm{in} .^{3}$, it becomes evident that few fibers of these densities have been made relative to the lightweight fibers approximating $0.1 \mathrm{lb} / \mathrm{in} .{ }^{3}$ density. To date, all whiskers of these densities are metallic. This poses another problem since metallic whiskers are most easily damaged or potentially reactive with metal matrix materials. They would have to be protected by some diffusion barrier or coating. In any case, the incentive to work with high density metallic whiskers at present is not very great because of the density penalty. Some of the high strength filaments with densities of $0.3 \mathrm{lb} / \mathrm{in}^{3}$ include columbium alloys, steels, and superalloys. Of these filaments or wires, only steels have been made with strengths of 575:000 psi although stainless steels such as AFC-77 are very close to this strength. To satisfy the strength design criterion only extremely strong metallic filaments can be considered for reinforcing structural materials and then only with lightweight matrix materials. Large volume percents of fibers would lower the required fiber strength, and low volume per - 
cents make fiber strength requirements almost impossible to achieve with today's fibers. The promise of the future is indicated by unusual results reported for columbium which has a strength of $2 \times 10^{6}$ psi when drawn to $500 \mathrm{~A}$ size in a copper matrix (ref. 13). Tungsten fibers have been drawn to fine diameters and for a material with a density approximating $0.7 \mathrm{lb} / \mathrm{in}^{3}{ }^{3}$ have surprisingly good specific strength. A strength of 500000 psi is readily achievable for this material and a result of $1 \times 10^{6}$ psi has been reported for an individual laboratory fiber. Although tungsten whiskers have been made, they have not been considered seriously for structures. High density materials such as compounds of carbides, borides, carboborides, carbonitrides, nitrides silicides, and intermetallic compounds have densities ranging from very low to that of tungsten, but none of these materials have been fibered, much less made into whiskers. Thus, for all the requirements calculated for the heavier fibers $\left(0.3 \mathrm{lb} / \mathrm{in}^{3}{ }^{3}\right.$ and above), only the steels have the strengths adequate to meet the design criterion for the lightweight composites.

\section{Modulus of Elasticity Requirements}

The trends relating to the design of a material with a specific modulus of $167 \times 10^{6}$ inches are shown in Fig. 3. This was obtained using the modulus and density values shown in table II. In general, they are similar to those for the strength curves of Fig.2. Briefly a composite with greater $\mathrm{v} / \mathrm{o}$ fibers requires a fiber with a lesser modulus than one with low volume percentage. Increasing the matrix density requires fibers of increasing moduli and, where the matrix density is held constant but the fiber density is increased, the required modulus increases are substantial. The values of the calculated moduli for fibers to meet the modulus design criterion are given in table $\mathrm{V}$ 
for 20 and $50 \mathrm{v} / \mathrm{o}$ fiber composites. In addition, available or possible future fibers that could meet the design requirements are also indicated. Although all calculated fiber strengths necessary to produce the strength design criterion were at least theoretically possible, the moduli possibilities are more limited. For today's state-of -the-art the diamond has the highest known modulus of $170 \times 10^{6} \mathrm{psi}$. Tungsten carbide in bulk form is known to have a modulus of $100 \times 10^{6} \mathrm{psi}$, and whiskers of silicon carbide of $\mathrm{Al}_{2} \mathrm{O}_{3}$ have been reported to have moduli of $150 \times 10^{6} \mathrm{psi}$. The theoretical possibilities for future, greater maximum modulus values for any given material is not known.

The type of fiber required to achieve the design criterion with a light matrix $\left(0.1 \mathrm{lb} / \mathrm{in}^{3}{ }^{3}\right)$ and with $50 \mathrm{v} / 0$ fibers is one with a very low modulus of $23 \times 10^{6}$ psi. Almost all fibers except the glasses listed in table II have moduli above this value. With time too it is conceivable that special glasses will be developed with moduli this high. Mullite fibers (aluminum silicates) with moduli averaging $22 \times 10^{6}$ psi and as high as $27 \times 10^{6}$ have been produced recently。

The moduli of elasticity values of most of the lightweight fibers are adequate to meet the design criterion for 20 volume percent fibers and a lightweight matrix, or, $50 \mathrm{v} / \mathrm{o}$ intermediate weight matrix materials。Moduli of over $87 \times 10^{6}$ or $97 \times 10^{6}$ psi have been achieved for graphitic fibers and whiskers and for $\mathrm{Al}_{2} \mathrm{O}_{3}$ and SiC whiskers. Such values are for experimental materials rather than materials produced in quantities. Coming to the high density fibers, high moduli are required to achieve design criterion as shown in table V。 Presently there are no known available fibers of densities of 0.3 or $0.6 \mathrm{lb} / \mathrm{in}^{3}{ }^{3}$ with extremely high moduli of elasticity。 As needs arise 
for high modulus, high strength materials, particularly for high temperatures, high density carbides, borides, oxides, and other compounds in whiskers or filament form may well be made to have moduli in the 50 to 100 million psi range. Actually, if a low density fiber is stable in a given matrix for a specific use condition, it is obviously not desirable to use higher density fibers.

\section{Possible Composites That Would Meet Design Criteria} for Both Specific Strength and Modulus

The composites consisting of fibers and matrices, each with a density of approximately $0.1 \mathrm{lb} /$ in. $^{3}$ (type 1 composites - see tables IV and V), could be constructed from all of the ceramic whiskers indicated in table III for both 20 and 50 volume percent fiber composites. The filaments $\mathrm{B}, \mathrm{B}{ }_{4} \mathrm{C}$, SiC coated $\mathrm{B}$, SiC, and graphite could be used for $50 \mathrm{v} / \mathrm{o}$ fiber composites. Composites with fibers of $0.1 \mathrm{lb} / \mathrm{in}^{3}{ }^{3}$ density and a matrix of $0.3 \mathrm{lb} / \mathrm{in}^{3}{ }^{3}$ (type $2 \mathrm{com}$ posites) could be made from all ceramic whiskers listed in table III for $50 \mathrm{v} / \mathrm{o}$ composites, but only $\mathrm{Al}_{2} \mathrm{O}_{3}$, $\mathrm{SiC}$, and graphite whiskers for $20 \mathrm{v} / \mathrm{o}$ composites. Filaments of B and SiC coated B might be used to make $50 \mathrm{v} / 0$ composites, if very select materials were used. With a $0.6 \mathrm{lb} / \mathrm{in}_{\circ}{ }^{3}$ matrix (type 3 composite) only the $\mathrm{Al}_{2} \mathrm{O}_{3}, \mathrm{SiC}$, and graphite whiskers would be possible fibers for $50 \mathrm{v} / \mathrm{o}$ composites.

On the assumption that high strength whiskers could be segregated from "as grown" whiskers so that high average strength batches of whiskers could be used, they would give many more composites the strength or modulus to achieve the design criteria than could today's filaments. For both filaments and whiskers there are practical material limitations, however. With today's 
state-of -the-art, for example, it is difficult to even pact $50 \mathrm{v} / \mathrm{o}$ whiskers into a composite. Further, to those interested in making composites from available, relatively commercial fibers, only a limited number are available. These include graphite, $\mathrm{B}, \mathrm{SiC}$ coated $\mathrm{B}$, and $\mathrm{SiC}$ filaments and $\mathrm{Al}_{2} \mathrm{O}_{3}$ and $\mathrm{SiC}$ whiskers.

\section{MATERIALS DESIGNED FOR STRESS RUPTURE STRENGTH}

Potential engines for the SST, VSTOL, VTOL, and others require greater operating temperatures to produce more thrust per pound of engines. One method for increasing the turbine inlet temperatures is to cool certain parts, particularly turbine blades and vanes. A significant energy loss results from cooling, however, and presumably, too, the design and construction of turbine discs to accommodate cooled blades would pose problems that solid blades would circumvent. Within the last 20 years the use-temperature for turbine blades has increased about $400^{\circ} \mathrm{F}$ or about $20^{\circ}$ per year. Today it is not unusual for a gas turbine to operate at an $1800^{\circ} \mathrm{F}$ material temperature. It will be made evident that composites offer a potential for increasing the use temperature of the blades substantially.

The temperature profile of a turbine blade, along with a stress distribution in the airfoil are schematically illustrated in Fig. 4. The highest stress occurs near the root and zero stress occurs at the tip, whereas the highest temperature occurring at the tip and the lower temperature at the root. For different combinations of stress and temperature, the material in the blade would have different times-to-rupture or stress-rupture lives. From stress-rupture data the U-curve of the figure is shown representing the life of the material in the different portions of the blade. The lower portion of this life curve defines the critical zone of the blade where the life 
should be the lowest. It is this zone that is of primary concern in this paper. Typical stresses in gas turbine blades in the critical zone ranges from 15000 to 20000 psi for nickel base or other superalloy materials. Again, as in the case of the low temperature composites the density of the composite is most important. Comparisons of materials must again be made on the basis of specific strengths. Figure 5 shows some plots of the strengths of different superalloy materials. In addition, horizontal lines representing the specific strengths of 50000 and 67000 inches (the equivalent of 15000 to 20000 psi stress range for alloys of nominally $0.3 \mathrm{lb} / \mathrm{in}_{\circ}{ }^{3}$ density) are shown. Intersection of these lines with the strength plots of the superalloys indicates the maximum "use-temperature" of the alloy to a given specific strength. Udimet $700(\mathrm{U}-700)$ is a wrought alloy and IN:100 a cast alloy. The strongest of the alloys represented by the curves is the cast alloy NASATRW alloy VI A which would have a blade use temperature of $1870^{\circ} \mathrm{F}$.

For this example the arbitrarily selected criterion for the design of a composite will be a use temperature of $2000^{\circ} \mathrm{F}$ for 1000 hours for a specific stress-rupture strength of 50000 inches. This use-temperature of this material would be $200^{\circ} \mathrm{F}$ higher than conventional alloys and $130^{\circ} \mathrm{F}$ higher than the best alloy indicated.

The high temperature material will be designed using the concepts illus trated in Fig. 6 (ref. 4). This is a schematic illustration of the strength of a fiber, a matrix, and a composite material made from the fiber and matrix, plotted on a logarithmic scale, versus homologous test temperatures. Homologous temperature is the ratio of the test temperature in degrees absolute of the material to the absolute melting temperature of the material. The scale for 
the matrix temperature of the composite ranges from 0.2 to 1 in this figure. At 1 the matrix would melt and would have no strength. The fiber temperature in a composite would, in this figure, range from 0.07 to 0.35 of its melting point, the latter temperature being equivalent to the melting point of the matrix. Thus, a high melting point fiber embedded in a low melting point matrix would have a high fraction of its strength left when the matrix melts. At temperatures below the matrix melting point the composites should have strengths between the strength of the matrix and the strength of the fibers according to Eq. (3), for stress rupture conditions (see also ref. 10). Using the same concept as for the room temperature design criterion, Eq. (4) can again be used if the stress rupture strengths' of fiber and matrix materials for a given time are used for values of $\sigma$ and $\sigma_{\mathrm{m}}^{*}$

In this example there is no option for varying the density of matrix since it is required that it be an oxidation resistant superalloy. However, large variations in matrix strengths at $2000^{\circ} \mathrm{F}$ are possible depending on the type of alloy selected. For the calculations a low strength matrix (400 psi) was used for one example and a high strength matrix (8000 psi) for another. Whereas in the past example for low temperature composites, matrix strengths $\left(\sigma_{\mathrm{m}}^{*}\right)$ varied with the matrix densities (since the type and strength of alloy would change with density), the importance of using a high strength matrix was not readily apparent from the calculations. In this high temperature case, however, the matrix density is constant.

Fig. 7 shows a plot of a calculated fiber strengths necessary to give a superalloy matrix composite a specific strength of 50000 inches. Again, lower strength fibers are required for high volume percent composites and 
vice versa. Also, heavier fibers must be considerably stronger than lighter weight fibers. The stress-rupture strength of a $0.3 \mathrm{lb} / \mathrm{in}^{3}$ fiber must be 10000 psi greater than a $0.1 \mathrm{lb} / \mathrm{in}^{3}{ }^{3}$ fiber. Similarly, a $0.7 \mathrm{lb} / \mathrm{in}^{3}{ }^{3}$ fiber must be 20000 and 30000 psi stronger than a 0.3 and $0.1 \mathrm{lb} / \mathrm{in}^{3}$ fiber, respectively. Table VI shows the fiber strengths needed to give 50 and 20 v/o fiber composites the design specific stress-rupture strength under discussion. The importance of a high strength matrix relative to a low strength matrix is evident both from Fig. 7 and Table VI. For example, the required fiber strengths to reinforce a low strength matrix rather than a high strength would have to be 8000 psi more for a $50 \mathrm{v} / \mathrm{o}$ fiber composite and 30,000 psi more for a $20 \mathrm{v} / \mathrm{o}$ composite. Another interesting point from these calculations can be seen in Fig. 7 which shows that at a constant fiber stress level in the range of 75000 to 170000 psi and for constant fiber density, the strong matrix composite would require about half the fibers that the weak matrix would require. The concept of varying the matrix strength then could be very important, particularly for high temperature alloys or for creeprupture applications. Consider for example, that a typical superalloy matrix might have a strength of 4000 psi at a temperature of $2000^{\circ} \mathrm{F}$ for 1000 hours. If this alloy could be heat treated to have a significant increase in strength, one could lower the volume percent of fibers drastically or use a lower strength, less expensive fibers in the material. Sometimes it is possible to improve the stress-rupture strength of superalloys for use at $2000^{\circ} \mathrm{F}$ or above by heat treatments. More significant strength increases can be obtained by dispersion strengthening, however。

For example, in an experimental development program, superalloys, dispersion strengthened with thorium oxide, have been produced with strengths 
as high as 17000 psi for 100 hours at $2000^{\circ}$ F (ref. 14). Assuming, conservatively, that 12000 psi would be a good 1000-hour strength for this type of material, it can be shown that, for the design criterion of 50000 inches and using a tungsten fiber, 13.1 v/o of fibers would be required for the conventional superalloy to achieve the design strength whereas only 3.3 percent would be required for the dispersion strengthened materials. Thus, in addition to conducting research and development programs associated with vary ing the volume percents, fibers, the densities of the fibers, the strengths, etc., it is well worth considering research on matrix materials, particularly for those temperature ranges and for those alloy systems where heat treatment subsequent to fabrication might increase the strength of the matrix.

Many bulk refractory metals and ceramics have the strength to meet the 50000 inch criterion but have never been made in fiber form. Because most emphasis has been given to fiber materials for use in low temperature portions of the engine, relatively little stress-rupture data exist for fibers at temperatures as high as $2000^{\circ} \mathrm{F}$. It is relatively safe to predict that refractory metals would, if they could be fibered, have properties that would equal or exceed those of the bulk materials. The bigger question is whether a given refractory alloy or material can be drawn or fibered. Generally, a bulk refractory material with properties good enough to meet the design criterion can be considered a candidate fiber material.

Whiskers, generally, should have excellent high temperature strength but have not been tested at high temperatures. Many filaments and whiskers, then, listed in the table must be considered as potentially good fibers at $2000^{\circ} \mathrm{F}$. 
Actually very little stress-rupture testing of fibers at $2000^{\circ} \mathrm{F}$ has been done, most of the tests being for 100 hours or less. It is fairly safe, how ever, to extrapolate such data to 1000-hour life. The extrapolated 1000-hour strengths of some fiber materials, most of which meet the design criterion indicated in table VI, are presented in Fig。 8 (ref。15). Although most of these are tungsten base alloys with a high density, their high temperature strength is so great that their specific strength is high. For $50 \mathrm{v} / \mathrm{o}$ fiber composites, all fibers except the $\mathrm{W}-24 \mathrm{Re}-2 \mathrm{ThO}_{2}$ have the necessary strength. For $20 \mathrm{v} / \mathrm{o}$ composites, only two of the fibers, $\mathrm{W}-3 \mathrm{Re}$ and $\mathrm{W}-2 \mathrm{ThO}_{2}$, are adequate. Those fibers that contain $\mathrm{ThO}_{2}$ are dispersion strengthened materials, a general class of materials that warrants development for high temperature fiber reinforcing materials as well as matrices. Molybdenum alloys with intermediate densities between that of tungsten alloys and columbium alloys should also be adequate for reinforcement of superalloys. The columbium alloys FS-85, and AS-30 would be adequate for $50 \mathrm{v} / \mathrm{o}$ composites but not $20 \mathrm{v} / \mathrm{o}$ composites.

Efforts are being sponsored by NASA to draw some of the newer high strength refractory alloys into fibers. Two potential fiber materials of note are the tantalum alloy $\mathrm{T}-\mathbf{2 2 2}$ and the columbium alloy $\mathrm{XB}-88$ 。 New tungsten alloys are also under development for fiber potential.

As was the case for high density filaments, there is little incentive to produce whiskers of high densities. Relatively little is being done with metallic whiskers of any type for reinforcement materials.

Both whiskers and filaments of many of the low density ceramic materials should have potential for high temperature use. Those listed as ${ }^{81}$ possible 8 in the table appear to be likely candidate materials. Actually, for high tem- 
perature compatibility with the matrix, a material should have the best thermodynamic stability possible; oxides fall into this category. Most of the ceramic fibers, when tested outside a matrix, maintain their strength at high temperatures; in fact, some are as strong at high temperature (e.g。, 1500 to $3000^{\circ} \mathrm{F}$ in tension) as they are at low temperatures. Presumably they should have excellent stress-rupture properties also. Unfortunately, as was mentioned earlier, some of the lightest weight and strongest materials are most incompatible with metals at high temperatures. Coatings are necessary for many of the lightweight materials if they are ever to be used under stress-rupture conditions. Lightweight materials listed in the table as possible reinforcements were listed on the assumption that their $2000^{\circ} \mathrm{F}$ stress-rupture properties should relate somewhat to the high temperature tensile properties of filaments of the same materials. Actually, both filamentary and whisker ceramic types of fibers would be expected to have the properties for the design criterion. Single crystal $\mathrm{Al}_{2} \mathrm{O}_{3}$ monofilaments and flame polished crystals may prove to have good high temperature strength because of their potential stability at high temperature.

\section{FABRICATION CONSIDERATIONS FOR COMPOSITE MATERIALS}

The designer of composites can be pleased that there are so many different types of fibers and matrix materials to choose from. However, because not all desired combinations of materials can be successfully consolidated, he must know something of the metallurgical, chemical, and mechanical problems that must be faced to produce a composite with a designed property. An ideal composite, in a sense, is one in which the matrix and fiber are not damaged metallurgically or mechanically during fabrication or during use to form a product with properties less than those expected from the properties of the fiber and matrix. 
Unfortunately, most fiber-metal combinations of interest are reactive; the reactions being time and temperature dependent. As a result, varying degrees of damage may be done to the fiber or the matrix during fabrication. If molten liquid infiltration about fibers is used to consolidate the composite, the fiber under some circumstances may dissolve completely or partially into the molten matrix. On the other hand, if the process is carried out very rapidly, the liquid can sometimes be chilled to low temperatures before it damages the fibers. Solid state bonding of a matrix about fibers, too, is usually accomplished at temperatures high enough to damage fibers. Partial solutioning of the fiber in the matrix or vice versa is possible. Depending on the materials, metals may penetrate grain boundaries of fibers or react to form brittle peripheral compounds, voids, notches, and other defects. Some of the lowest density, high strength, high modulous fibers (e.g。, graphite, boron, beryllium) tend to react with many metals when consolidated into composites or when composites containing them are used at high temperatures. Obviously, fabrication damage would be minimized if low temperatures of consolidation or short times at high temperature could be used. Electroplating (or electroforming), high energy rate compaction, and plasma spraying are examples of "cold" consolidation methods. Such methods are no panacea either, for example, electroplating can form a composite with voids or produce an impure matrix with oxides, dissolved hydrogen, or other impurities from the plating operation; high energy rate compaction can damage fibers.

In addition to the chemical-metallurgical reactions induced by thermal conditions during consolidation, mechanical problems (e.g., the crushing of fibers during hot pressing and the abrasion of fiber surfaces) may 
cause irreparable harm to the composite. More important than is appreciated generally isthe thermal stressing of composites due to different coefficients of thermal expansion of fiber and matrix, which can severely damage a composite. When fibers within cross plies, or oriented fibers too, touch each other or are too close to each other, they can damage the composite by causing stress concentrations or by embrittling the matrix. Whiskers are perhaps more sensitive to damage than many filaments, and in addition because of their variations in size and quality, give the composite fabricator special orientation problems and statistical problems (strength variations) as well.

With all of the above potential problems, it might well be wondered how successful have been the attempts to produce composites. Although it is not the purpose of this paper to review the status of fiber reinforced composites, it is felt that brief mention of some of the successes attained in the field be made. Since this paper is concerned with materials for gas turbines, it might be well to make comparisons not only to the design criteria selected but also to presently used alloys. A principal material used for the fan and the compressor is $\mathrm{Ti}-6 \mathrm{Al}-4 \mathrm{~V}$ alloy, whereas there are several superalloys that could be considered as turbine blade materials.

Aluminum matrix composites have been investigated to greater degree than others, principally because of the light weight of aluminum. Almost all of these composites, and there have been hundreds of them, have had strengths greater than those of the matrix. Many have achieved rule-of mixture strengths while others have had properties greater than those of the strongest aluminum alloys. A number of investigators have produced products with specific strengths greater than $1.5 \times 10^{6}$, and a few, with almost 
$3 \times 10^{6}$ inches. The successfully used fibers were lightweight $\mathrm{SiO}_{2}$, Boron, and SiC coated B. Such results certainly would be expected from the earlier calculations. On the other hand, very few whisker-aluminum alloy composites have exceeded the specific strength of the titanium alloy (860 000 in.). In one case surveyed, however, the whisker composite has almost achieved the design criterion $\left(1.5 \times 10^{6}\right.$ in.).

Most titanium matrix composites have not been made strong enough to exceed the specific strength of the titanium alloy and no surveyed specific strength properties were found as great as $1,5 \times 10^{6}$ inches. Such materials should, however, have greater strengths, a fact which suggests redoubling efforts in the titanium field. The same general comments made for titanium composites can be made for nickel composites. They have not been made with strengths significantly above those of the best superalloys. A few have specific strengths greater than that of the titanium alloys, but none have been made to achieve the design criterion. Both titanium and nickel- or cobaltbase composite materials have higher temperature strength potentials than aluminum composites, however. Generally, there have been fabrication and compatibility problems with these materials and many have tended to have less than optimum strength. Nickel and cobalt-base matrix materials have achieved rule-of-mixture strengths, but such strengths are not great enough to compensate for their high density. Although this paper is concerned with two extremes of temperatures, room temperature and $2000^{\circ} \mathrm{F}$, it should be mentioned that some composites have greater relative superiority on specific strength basis at high temperatures than at low temperatures.

Specific modulus results obtained are relatively better than specific strength results for aluminum, titanium, and cobalt- and nickel-base com- 
posites. Values well in excess of the specific modulus of titanium, $103 \times 10^{6}$ inches, one standard for comparison, have been achieved with several filament and whisker materials by many investigators. The specific modulus criterion of $167 \times 10^{6}$ inches has also been exceeded in many cases for both aluminum and titanium matrix composites and also but to a lesser degree for nickel and cobalt base materials. Since higher specific modulus values permit weight reductions, such results are encouraging. Good composites have been made with specific moduli ranging from $150 \times 10^{6}$ to over $400 \times 10^{6}$ inches.

At the high tẹmperature level of $2000^{\circ} \mathrm{F}$, relatively little has been done with fibers or with composites. In work conducted at the Lewis Research Center, experience with high temperature composites has been encouraging (refs. 16 and 17). For example, one composite composition with $\mathrm{W}+2 \mathrm{ThO}_{2}$ fibers has been made with a strength to density ratio of 60000 inches for 1000 hours at $2000^{\circ} \mathrm{F}$ (ref, 17). This is a greater value than that of any superalloy or dispersion strengthened material of comparable melting point。

A significant number of investigations have been made by others of properties such as fatigue and impact. Results in many cases are encouraging. Much more must be done in these areas and in addition it is believed greater emphasis should be given to prototype studies.

\section{CONCLUDING REMARKS}

It was demonstrated, on a first approximation basis, that numerous composite materials with specific tensile or stress-rupture strengths, and specific moduli superior to those of conventional materials can be "idesigned" from fiber and matrix materials available today. Not all possible combinations of materials that have tensile, or other properties of interest can be 
used, largely because of compatibility problems. Yet the choice of fiber and matrix materials is so large for some composites that the materials engineer can often consider several combinations of constituents to achieve his desired properties. Perhaps the first step in designing a composite is to calculate the fiber strengths or moduli to achieve design goals. This permits a determination of which existing fibers and matrices of given densities can be used for composites with different volume percentages of fibers. Having many options for choice and quantities of fibers also permits selection of different fabrication methods and the production of products with desired properties other than strength or modulus. Overdesign can be avoided and, in some cases, permit cost reduction. In summary, constituent materials are available and the state-of-the-art is such that composite materials should be seriously considered and evaluated for the more severe use areas of such sophisticated devices as turbojet engines.

\section{REFERENCES}

1. W. A. Compton, R. J. Akins, and H. Mnew, "Metal-Matrix Composite Materials for Aircraft Compressor Blades, " Advanced Fibrous Reinforced Composites, SAMPE, Vol. 10, Western Periodicals Co., North Hollywood, Calif., 1966, pp. C -61 to C -76 .

2. A. Kelly and W. R. Tyson, "Fiber-Strengthened Materials," HighStrength Materials, 2nd International Materials Conference, V. F V. F. Zackay, ed., John Wiley \& Sons, Inc., New York, N. Y., 1965, pp. $578-602$. 
3. R. H. Krock and L. J. Broutman, "Principles of Composites and Composite Reinforcement," Modern Composite Materials, L. J.Broutman and R. H. Krock, eds., Addison-Wesley Publ. Co., Reading, Mass., 1967, pp. 3-26.

4. J. W. Weeton and R. A. Signorelli, "Fiber-Metal Composite Materials," NASA TN D-3530, 1966.

5. D. W. Petrasek, R. A. Signorelli, and J. W. Weeton, "Metallurgical and Geometrical Factors Affecting Elevated-Temperature Tensile Properties of Discontinuous-Fiber Composites," NASA TN D-3886, 1967. (also D. W. Petrasek, R. A. Signorelli, and J. W. Weeton, "Metallurgical and Geometrical Factors Affecting Elevated Temperature Tensile Properties of Discontinuous Tungsten Fiber Reinforced Composites, " FiberStrengthened Metallic Composites, Special Technical Publication No. 427, ASTM, 1967, pp. 149-175.)

6. J. M. S. Keen, "The Use of Composite Materials in Aero-Engines," SAE Paper 670333, April, 1967.

7. Anon., "Composites Going into Rolls RB 211 Engine Parts," Aerospace Technology, vol. 21, no. 25, June 3, 1968, pp. 22, 24.

8. R. W. Jech and R. A. Signorelli, "The Effect of Interfiber Distance and Temperature on the Critical Aspect Ratio in Composites, " NASA TN D-4548, 1968 .

9. R. W. Jech, D. L. McDanels, and J.W. Weeton, "Fiber Reinforced Composites, " Composite Materials and Composite Structures, Proceedings of the Sixth Sagamore Ordnance Materials Research Conference, Racquette Lake, New York, August 18-21, 1958, Syracuse University Research Institute Rep。MET661-601, 1959, pp。116-143. 
(Also D. L. McDanels, R.W. Jech, and J.W. Weeton, "Metals Reinforced with Fibers, " Metal Progress, vol。78, no.6, December, 1960, pp. 118-121; and D. L. McDanels, R. W. Jech, and J. W. Weeton, 'Stress-Strain Behavior of Tungsten-Fiber-Reinforced Copper Composites," NASA TN D-1881, 1963.)

10. D. L. McDanels, R. A. Signorelli, and J.W.Weeton, Analysis of Stress-Rupture and Creep Properties of Tungsten-Fiber-Reinforced Copper Composites," NASA TN D-4173, 1967.

(Also D. L. McDanels, R. A. Signorelli, and J. W. Weeton, "Analysis of Stress-Rupture and Creep Properties of Tungsten Fiber Reinforced Copper Composites, " Fiber-Strengthened Metallic Composites, Special Technical Publication No.427, ASTM, 1967, pp.124-148。)

11. C. C. Chamis, "Failure Criteria for Filamentary Composites," NASA TN D-5367, 1969.

12. W. H. Sutton and H。W. Rauch, Sr., "Review of Current Developments in New Refraciory Fibers and Their Utilization as High Temperature Reinforcements, "Advanced Fibrous Reinforced Composites, SAMPE, Vol. 10, Western Periodical Co., North Hollywood, Calif., 1966, pp. B-1 to $\mathrm{B}-13$.

13. H. E. Cline, B. P. Strauss, R. M. Rose, and J. Wulff, "Fabrication of an Ultra-Fine $\mathrm{Cb}-\mathrm{Cu}$ Composite by Drawing, "ASM Transactions, vol. 59, no. 1, March, 1966, pp.132-136. 
14. A. L. Mincher, "Research on Dispersion Strengthened Cobalt-Base Alloys, $"$ E. I. DuPont de Nemours and Co., AFML-TR-65-442, pt. 2, AD-811907, March, 1967.

15. D. W. Petrasek and R. A. Signorelli, "Stress-Rupture and Tensile Properties of Refractory-Metal Wires at $2000^{\circ}$ and $2200^{\circ} \mathrm{F}\left(1093^{\circ}\right.$ and $\left.1204^{\circ} \mathrm{C}\right), "$ NASA TN D-5139, 1969.

16. D. W. Petrasek, R. A. Signorelli, and J.W.Weeton, "RefractoryMetal-Fiber-Nickel-Base-Alloy Composites for use at High Temperatures," NASA TN D-4787, 1968.

17. D. W. Petrasek and R. A. Signorelli, "Tungsten Alloy Fiber Reinforced Nickel Base Alloy Composites for High Temperature Turbojet Engine Applications," paper presented at ASTM Symposium on Composite Testing and Design, New Orleans, Louisiana, Feb. 10-14, 1969. 
TABLE I、 - HIGH STRENGTH MATERIALS USED FOR STRUCTURES (BULK COMMERCIAL MATERIALS)

\begin{tabular}{|l|c|c|c|c|c|}
\hline Alloy & $\begin{array}{c}\text { UTS } \\
1000 \mathrm{psi}\end{array}$ & $\begin{array}{c}\text { Density } \\
\text { lb/in. }\end{array}$ & $\begin{array}{c}\text { UTS/density } \\
10^{6} \text { inches }\end{array}$ & $\begin{array}{c}\text { Modulus } \\
10^{6} \mathrm{psi}\end{array}$ & $\begin{array}{c}\text { Modulus/ } \\
\text { density } \\
10^{6} \text { inches }\end{array}$ \\
\hline Steels & 300 & 0.27 & 1.11 & 29.5 & 109 \\
\hline $\begin{array}{c}\text { Titanium alloy } \\
\text { Ti-6Al-4V }\end{array}$ & $140-200$ & $0.163-0.165$ & $0.86-1.21$ & 17 & 103 \\
\hline Aluminum alloy & 80 & 0.1 & 0.8 & 10 & 100 \\
\hline
\end{tabular}

TABLE II. - TYPES OF MATRICES AND PROPERTIES REQUIRED FOR CALCULATIONS OF FIBER STRENGTHS OR MODULI

\begin{tabular}{|c|c|c|c|c|}
\hline Matrix category & $\begin{array}{l}\text { Examples of } \\
\text { matrix materials }\end{array}$ & $\begin{array}{l}\text { Densities } \\
\text { (approx.) } \\
\text { (b/in. }{ }^{3} \text { ) }\end{array}$ & $\begin{array}{c}\text { Strength, } \\
\mathbf{\sigma}_{\mathbf{m}}^{*} \\
\text { psi }\end{array}$ & $\begin{array}{c}\text { Modulus } \\
\text { of elasticity } \\
10^{6} \mathrm{psi}\end{array}$ \\
\hline Low density & Aluminum alloys & 0.10 & 25000 & 10 \\
\hline Intermediate density & $\begin{array}{l}\text { Steels, superalloys, } \\
\text { columbium alloys }\end{array}$ & 0.30 & 60000 & 30 \\
\hline High density & Tantalum alloys & 0.60 & 150000 & 26 \\
\hline
\end{tabular}


TABLE III. - FIBERS FOR METAL-MATRIX COMPOSITES ${ }^{2}$

\begin{tabular}{|c|c|c|c|c|c|c|c|c|}
\hline Fiber & $\begin{array}{l}\text { Melting or } \\
\text { softening } \\
\text { point, } \\
F\end{array}$ & $\begin{array}{c}\text { Density, } \\
\text { 1b/in. } 3\end{array}$ & $\begin{array}{c}\text { Tensile } \\
\text { strength, } \\
10^{\sigma} \text { psi }\end{array}$ & $\begin{array}{l}\text { Specific } \\
\text { strength, } \\
\sigma / \rho, \\
106 \text { in. }\end{array}$ & $\begin{array}{l}\text { Young's } \\
\text { modulus, } \\
10^{6} \mathrm{psi}\end{array}$ & $\begin{array}{c}\text { Specific } \\
\text { modulus, } \\
E / \rho, \\
10^{6} \mathrm{in} .\end{array}$ & $\begin{array}{l}\text { Typical } \\
\text { cross } \\
\text { section, } \\
\text { microns }\end{array}$ & $\begin{array}{l}\text { Approximate } \\
\text { cost, } \\
\$ / 1 \mathrm{~b}\end{array}$ \\
\hline \multicolumn{9}{|c|}{ WHISKERS } \\
\hline $\begin{array}{l}\text { Ceramic } \\
\mathrm{Al}_{2} \mathrm{O}_{3} \\
\mathrm{BeO} \\
\mathrm{B} 4 \mathrm{C} \\
\mathrm{SiC} \\
\mathrm{Sl}_{3} \mathrm{~N}_{4} \\
\text { Graphite }\end{array}$ & $\begin{array}{l}3700 \\
4660 \\
4440 \\
4870 \\
3450 \\
6600\end{array}$ & $\begin{array}{r}0.143 \\
.103 \\
.091 \\
.116 \\
.115 \\
.060\end{array}$ & $\begin{array}{c}600-3500 \\
1900 \\
2000 \\
2000-6000 \\
700-2000 \\
2845\end{array}$ & $\begin{array}{c}4.2-24.5 \\
18.4 \\
21.5 \\
17.2-51.3 \\
6.1-17.4 \\
47.4\end{array}$ & $\begin{array}{c}60-150 \\
(62)^{\mathrm{d}} \\
50 \\
70 \\
70-150 \\
(70)^{\mathrm{d}} \\
40-55 \\
102\end{array}$ & $\begin{array}{c}420-1050 \\
(434)^{d} \\
485 \\
76: \\
600-1300 \\
(608)^{d} \\
34.9-47= \\
1700\end{array}$ & $\begin{array}{l}0.5-10 \\
10-30 \\
0.5-10 \\
1-10\end{array}$ & $\begin{array}{c}1000-12,000^{\circ} \\
11 z, 000 \\
.250 \\
100-200\end{array}$ \\
\hline $\begin{array}{c}\text { Metal } \\
\text { Cr } \\
\mathrm{Cu} \\
\mathrm{Fe} \\
\mathrm{Ni}\end{array}$ & $\begin{array}{l}3430 \\
1980 \\
2800 \\
2650\end{array}$ & $\begin{array}{r}0.260 \\
.322 \\
.283 \\
.324\end{array}$ & $\begin{array}{r}1290 \\
427 \\
1900 \\
560\end{array}$ & $\begin{array}{l}5.0 \\
1.3 \\
6.7 \\
1.7\end{array}$ & $\begin{array}{l}35 \\
18 \\
25 \\
31\end{array}$ & $\begin{array}{r}134 \\
56 \\
102 \\
: 6\end{array}$ & -n- & 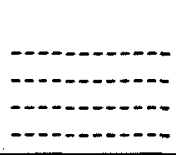 \\
\hline \multicolumn{9}{|c|}{ F TIAMENTS } \\
\hline $\begin{array}{l}\text { Glass } \\
\text { Type } \mathrm{E} \\
\text { Type } \mathrm{S} \\
\text { Mype 4H-1 } \\
\mathrm{SiO}_{2} \\
\text { Polycrystalline } \\
\mathrm{Al}_{2} \mathrm{O}_{3} \\
\mathrm{ZrO} \\
\text { BN } \\
\text { Grephite }\end{array}$ & $\begin{array}{l}1230 \\
1540 \\
1650 \\
3020 \\
\\
3700 \\
4800 \\
5400 \\
6600\end{array}$ & $\begin{array}{c}0.092 \\
.090 \\
.096 \\
.079 \\
. \\
0.114 \\
.175 \\
.069 \\
0.051-0.072\end{array}$ & $\begin{array}{c}500 \\
650 \\
730 \\
850 \\
\\
\\
300 \\
300 \\
200 \\
180-375\end{array}$ & $\begin{array}{c}5.4 \\
7.2 \\
7.6 \\
10.8 \\
\\
\\
2.6 \\
1.7 \\
2 . \therefore \\
3.5-5.8\end{array}$ & $\begin{array}{c}10.5 \\
12.6 \\
14.5 \\
10.5 \\
\\
25 \\
50 \\
13 \\
25-75\end{array}$ & $\begin{array}{c}114 \\
140 \\
151 \\
135 \\
\\
21 . \\
236 \\
1 \pm 8 \\
4.0-1040\end{array}$ & $\begin{array}{c}10 \\
10 \\
55 \\
\\
7 \\
7\end{array}$ & $\begin{array}{c}0-50 \\
1 \\
30 \\
175 \\
150-550\end{array}$ \\
\hline $\begin{array}{l}\text { Multiphase } \\
\text { B } \\
\text { B4C } \\
\text { SiC } \\
\text { SIC costed B } \\
\text { TiB2 }\end{array}$ & $\begin{array}{l}4170 \\
4440 \\
4870 \\
4170 \\
5400\end{array}$ & $\begin{array}{c}0.095 \\
.085 \\
0.125-0.127 \\
0.097 \\
.162\end{array}$ & $\begin{array}{c}400-580 \\
330 \\
350-600 \\
400-600 \\
150\end{array}$ & $\begin{array}{c}4.2-6.1 \\
3.9 \\
2.8-4.8 \\
4.1-6.2 \\
0.92\end{array}$ & $\begin{array}{c}55 \\
70 \\
60-67 \\
55 \\
74-50\end{array}$ & $\begin{array}{c}57: 2 \\
-24 \\
4.0-525 \\
570 \\
456-4.7\end{array}$ & $\begin{array}{c}100 \\
100-150 \\
109 \\
-\cdots\end{array}$ & $\begin{array}{c}250-500 \\
2100-3000 \\
600-520\end{array}$ \\
\hline $\begin{array}{l}\text { Metal } \\
\text { W } \\
\text { Mo } \\
\text { Rene 4I } \\
\text { Steel } \\
\text { Be }\end{array}$ & $\begin{array}{l}6150 \\
4750 \\
2460 \\
2550 \\
2240\end{array}$ & $\begin{array}{r}0.697 \\
.366 \\
.298 \\
.280 \\
.066\end{array}$ & $\begin{array}{l}580 \\
320 \\
290 \\
600 \\
195\end{array}$ & $\begin{array}{l}0.80 \\
0.20 \\
0.2 .1 \\
2.1 \\
2.9\end{array}$ & $\begin{array}{l}5 \\
52 \\
24 \\
2 . \\
35\end{array}$ & $\begin{array}{r}25 \\
141 \\
61 \\
103 \\
5 \% 0\end{array}$ & $\begin{array}{c}1 \div->500 \\
2 \div->00 \\
25 \\
15-40 \\
127\end{array}$ & $\begin{array}{l}20-710 \\
1 \div-6 \div 0 \\
600 \\
2-\div 0 \\
\sim 7090\end{array}$ \\
\hline $\begin{array}{l}\text { Monocrystals } \\
\mathrm{Al}_{2} \mathrm{O}_{3}\end{array}$ & 3700 & 0.143 & $400-600$ & $2.9-4.2$ & 67.5 & $4 / 2$ & $150-14$ & $0,0 \cap n^{2}$ \\
\hline
\end{tabular}

Modification of tabie-ref. 12 .

brices vary considerably with quentity, size, and time.

Much Iess in large quantities.

dSafe cesign value.

en 0.0005 in diam. tungsten core wire.

$f_{\text {Expeeted to be lower with time. }}$ 
TABLE IV. - CAICULATFE FIBER TEMSTIE STRENGTHS TO GIVE COMPOSITES A SPECIFIC STREMKIP OF 1,500,000 TNCHES AND CURRFINILY AVATIABLE OR POTENTIAL FIBERS WITH SUFFICIENI STRENGTHS ${ }^{\mathrm{a}}$

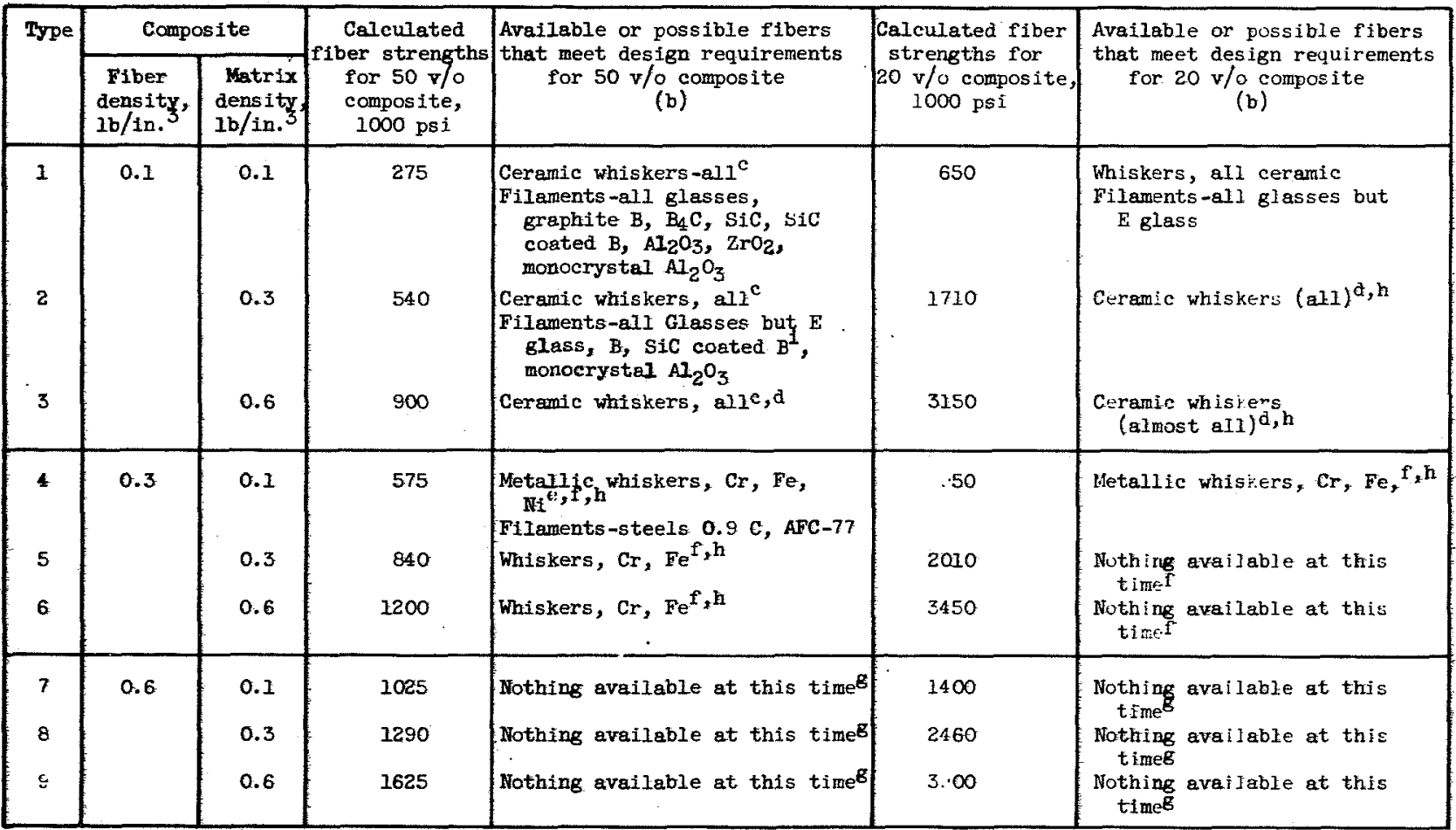

apefer to table III.

bAll ftbers listed have indicated strength or more, except where noted by fuotnotes.

c50 Percent whiskers are difficult to embed in composites, strength is adequate.

Whiskers must have average strengths calculated-usually large scatter of propertics.

Empractieal because metal whiskers damage easily-possible-eg. with coats.

fruture whiskers possible-eg. carbides, borides, nitrides, silicides, intermetallic compcunds, and sxides. C: fiter: dram "in situ" to $500 \AA$ diam. and $2 \times 10^{6}$ psi.

Game as $f$, except fewer possibilities. Also-where very high strength averages are rejuired; mithods of growing or segregating outstanding whiskers must be devised.

hroups of very high strength whiskers dffficult to separate from batches-at present.

${ }^{I_{B}}$ and SiC coated $B$ have strengths that in some cases exceed 500,000 p:i. 
TABLE V. - CAICULATED FIBER MODULI OF HEASTICITIES TO GIVE COMPOSITES A SPECIFIC MODULUS OF I67,000,000 INCHES AND CURPETHLY AVAFLABLE OR POTEANPIAL FIBERS WITH SUFFICIENI MODUH ${ }^{\mathrm{a}}$

\begin{tabular}{|c|c|c|c|c|c|c|}
\hline Type & \multicolumn{2}{|c|}{ Coupposite } & $\begin{array}{l}\text { Calculated } \\
\text { ftber moduli } \\
\text { for } 50 \mathrm{v} / 0 \\
\text { compostte, } \\
\text { I06 psi }\end{array}$ & $\begin{array}{l}\text { Avalleble or possible fibers } \\
\text { that meet design requirements } \\
\text { for } 50 \mathrm{v} / 0 \text { composite } \\
\text { (b) }\end{array}$ & $\begin{array}{l}\text { Calculated } \\
\text { fiber moduli } \\
\text { for } 20 \mathrm{v} / 0 \\
\text { composite, } \\
10^{6} \text { psi }\end{array}$ & $\begin{array}{l}\text { Aveilable or possible fibers } \\
\text { that meet design requirements } \\
\text { for } 20 \mathrm{v} / 0 \text { composite } \\
(\mathrm{b})\end{array}$ \\
\hline 3 & 0.1 & $\begin{array}{l}0.3 \\
0.6\end{array}$ & $\begin{array}{l}37 \\
87\end{array}$ & 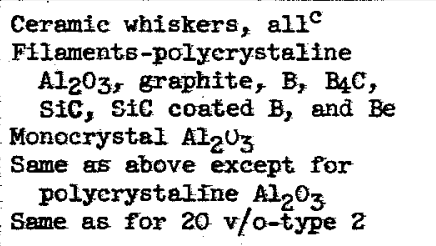 & $\begin{array}{r}97 \\
314\end{array}$ & $\begin{array}{l}\text { Same as for } 50 \text { v/o except for } \\
\mathrm{Al}_{2} \mathrm{O}_{3} \\
\text { Whiskers }{ }^{\mathrm{a}}-\mathrm{Al}_{2} \mathrm{O}_{3} \text {, SiC, graphite } \\
\text { Filaments-graphite possible } \\
\text { Not posstble }\end{array}$ \\
\hline $\begin{array}{l}5 \\
6\end{array}$ & 0.3 & $\begin{array}{l}0.1 \\
0.3 \\
0.6\end{array}$ & $\begin{array}{r}57 \\
70 \\
120\end{array}$ & $\begin{array}{l}\text { Nothing avaflable at this. } \\
\text { thme } \\
\text { Same as above } \\
\text { Probably not posstble }\end{array}$ & $\begin{array}{r}77 \\
131 \\
347\end{array}$ & $\begin{array}{l}\text { Same as for } 50 \text { v/o } \\
\text { Not possible } \\
\text { Not possiole }\end{array}$ \\
\hline
\end{tabular}

eqefer to teble EII.

baII ftbers Ifsted have indicated moduli or more, except where noted by foetnotes.

c50 Percent whiskers axe difficult to embed in composites.

diniskers ast have average moduIl equal to the calculated values.

Tuture vilskers possible-eg. carbides, borides, carboborides, carbonitrides, oxides, silicides, nitrides, intermetallic compounds; future filaments pessibIe - eg. monoerystal fllaments of preceding types of

interfals. Same materials will not be available for many years.

fliot posible - basied on today's knowledge. 
TABLE VI. - CALCUTATIED FIBER STRESS-RUPTURE STRENGTHS TO GIVE COMPOSTTES A SPECIFIC STRESS-RUPTURE STRENGTH OF 50,000 INCHES

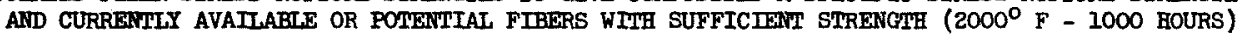

\begin{tabular}{|c|c|c|c|c|c|c|}
\hline \multirow[t]{2}{*}{ Type } & \multicolumn{2}{|c|}{ Composite } & \multirow{2}{*}{$\begin{array}{l}\text { Calculated fiber } \\
\text { stress-rupture } \\
\text { strensths for } \\
50 \mathrm{v} / 0 \text { composite, } \\
\text { psi }\end{array}$} & \multirow{2}{*}{$\begin{array}{l}\text { Available or possible fibers } \\
\text { that meet design requirements } \\
\text { for } 50 \mathrm{v} / 0 \text { composite } \\
\text { (a) }\end{array}$} & \multirow{2}{*}{$\begin{array}{c}\text { Calculated fiber } \\
\text { stress-rupture } \\
\text { strengths for } \\
20 \mathrm{v} / 0 \text { composite, } \\
\text {. ps1 }\end{array}$} & \multirow{2}{*}{$\begin{array}{l}\text { Avallable or possible fibers } \\
\text { that meet design requirements } \\
\text { for } 20 \mathrm{v} / 0 \text { composites } \\
\text { (a) }\end{array}$} \\
\hline & $\begin{array}{l}\text { Fiber } \\
\text { density, } \\
\text { Ib/In.3 }\end{array}$ & $\begin{array}{l}\text { Matrix } \\
\text { strength, } \\
\text { psi }\end{array}$ & & & & \\
\hline 2 & 0.1 & 8000 & 20,000 & 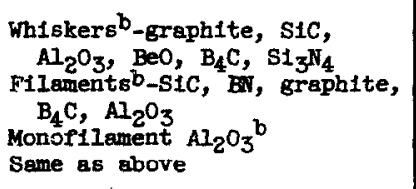 & 63,000 & $\begin{array}{l}\text { Same as for } 50 \mathrm{v} / 0 \text { composites } \\
\text { Same as for } 50 \mathrm{v} / 0 \text { composites }\end{array}$ \\
\hline 3 & 0.5 & 8000 & 30,000 & 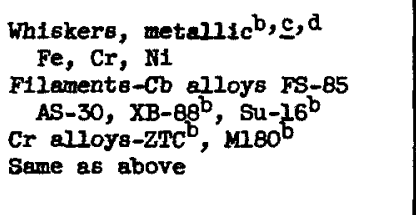 & 73,000 & $\begin{array}{l}\text { Whiskers }{ }^{d} \\
\text { F1lements }-\mathrm{Cb} \text { alloy } X R-88^{\mathrm{b}} \\
\text { Same as for type } 3-50 \mathrm{v} / 0 \\
\text { composites }\end{array}$ \\
\hline$\varepsilon$ & 0.7 & 8000 & 50,000 & 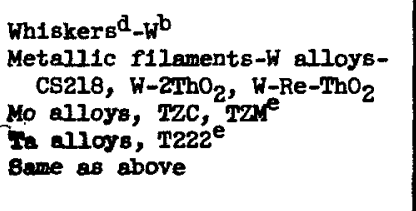 & 63,000 & $\begin{array}{l}\mathrm{W-ZThO} \\
\mathrm{Ta}-22 Z^{\mathrm{e}} \\
\mathrm{Mo-TZN^{ \textrm {e } }}\end{array}$ \\
\hline
\end{tabular}

all flbers indicated have indicated strengths or more, except where noted by footnotes.

bgtress-rupture strengthe are not know from actual tests-fibers estimated to achieve design strengths necessary on basis of tensile strengths and melting points.

CImpactical-metal whiskers are damaged too easily-might coat whiskers.

druture wiskers and filaments of eppropriate densities may someday be made of carbides, nitrides, oxides, silicides, Intersetallic coupounds, or combined compounds.

Tover density than $0.7 \mathrm{lb} / \mathrm{in} .3^{3}$-should have adequate strength. 


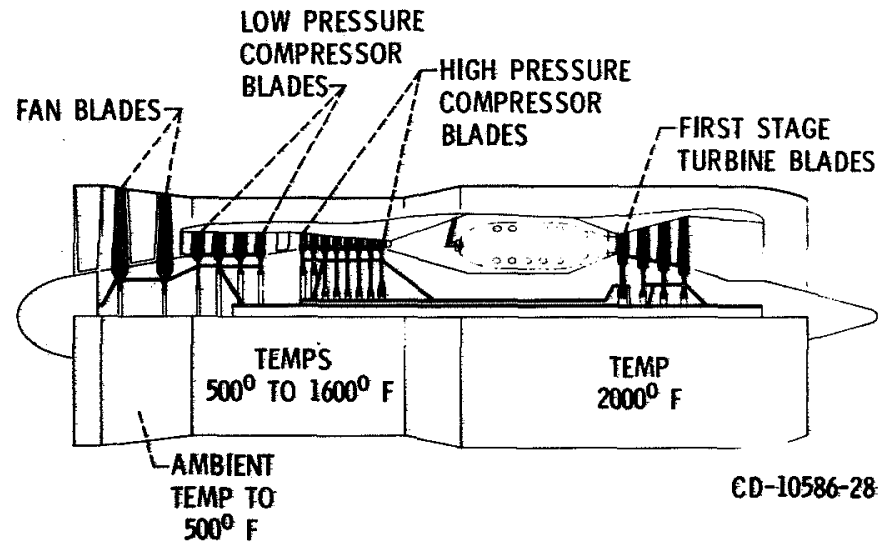

Eigure E. - Schematic illustration showing rotating blades and other components of engine. Temperatures indicated are for blade temperature of advanced supersonic engine. 


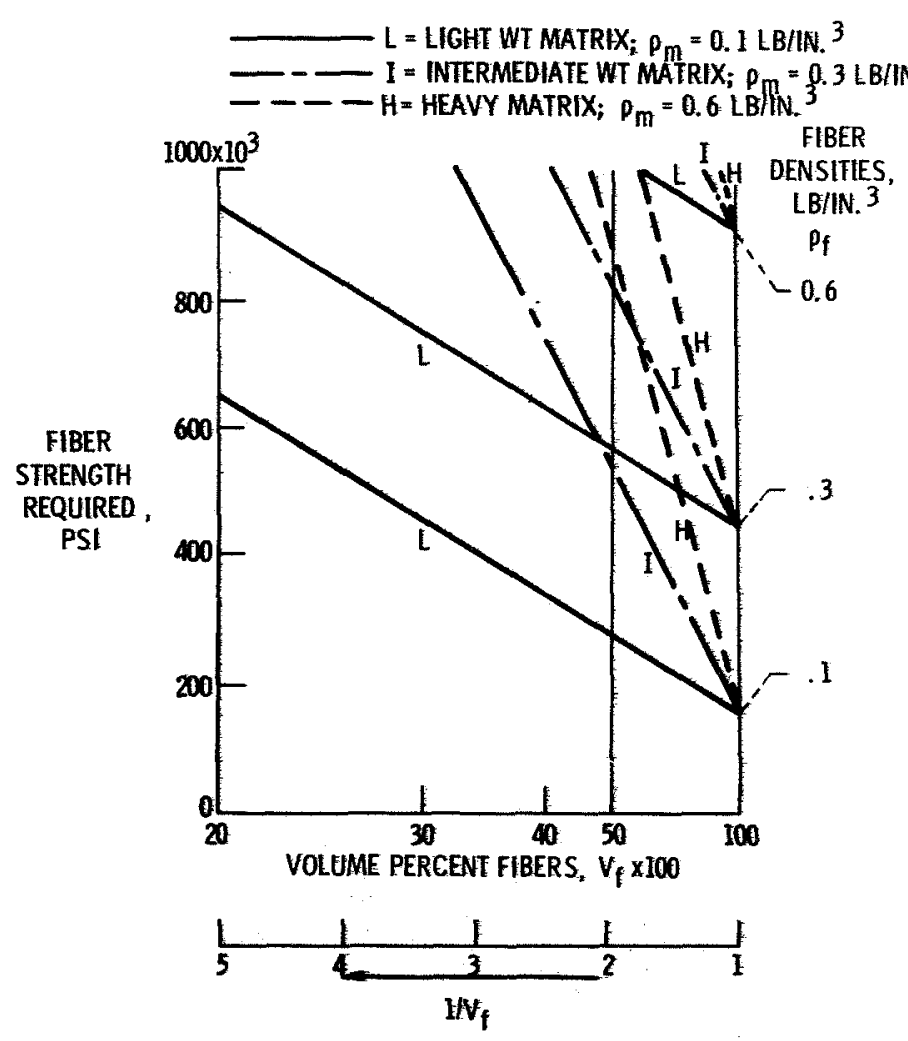

Figure 2. - Galculated fiber strengths required to produce high specific-strength composites. A specific strength of $1.5 \times 10^{6}$ inches is the eriterion used for the calculations. 


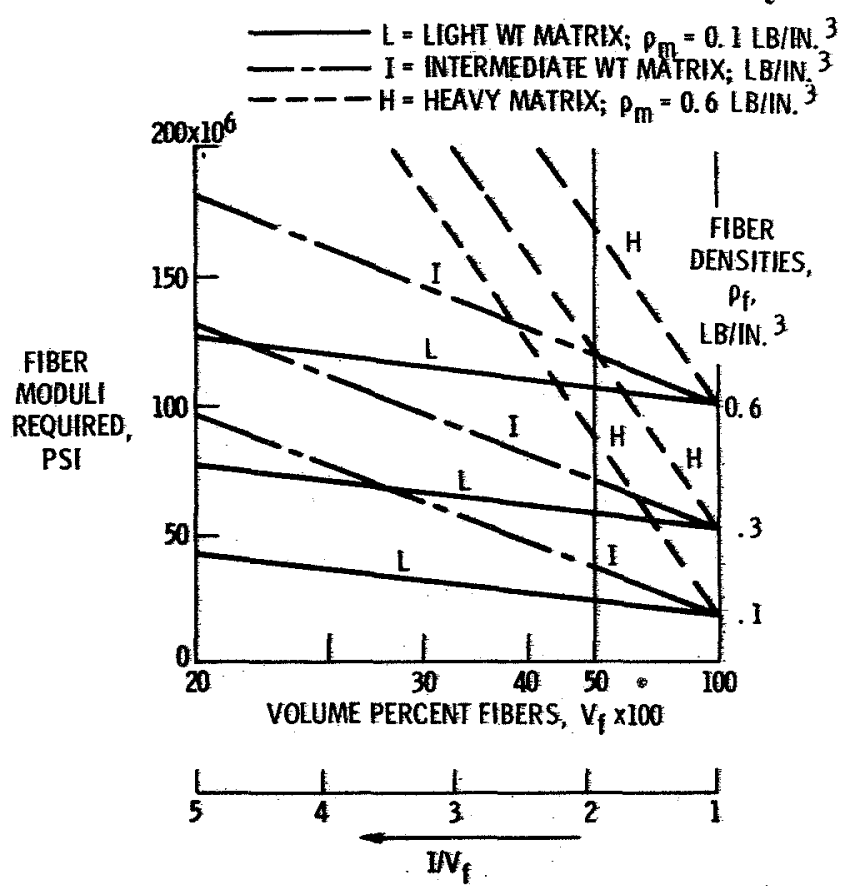

Figure 3. - Calculated tiber modulit required to producehigh specific modulus composites. A specific modulas of $167 \times 10^{\circ}$ inches is the criterion used for the calculations. 


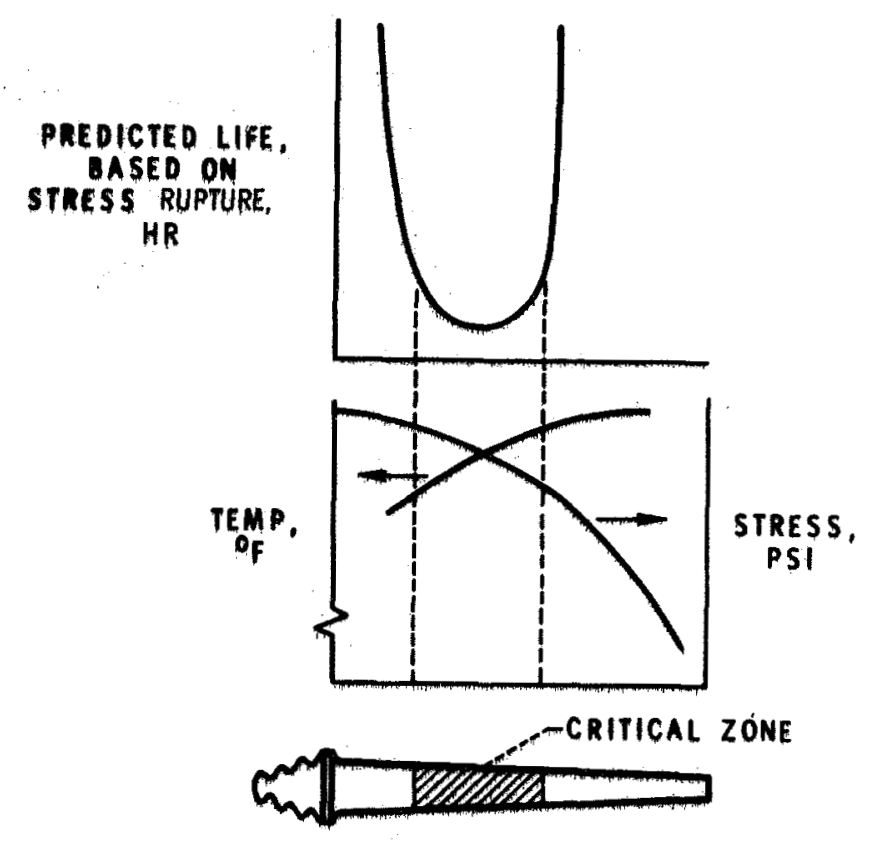

Figure 4. - Crritical zone of turbine blades. 


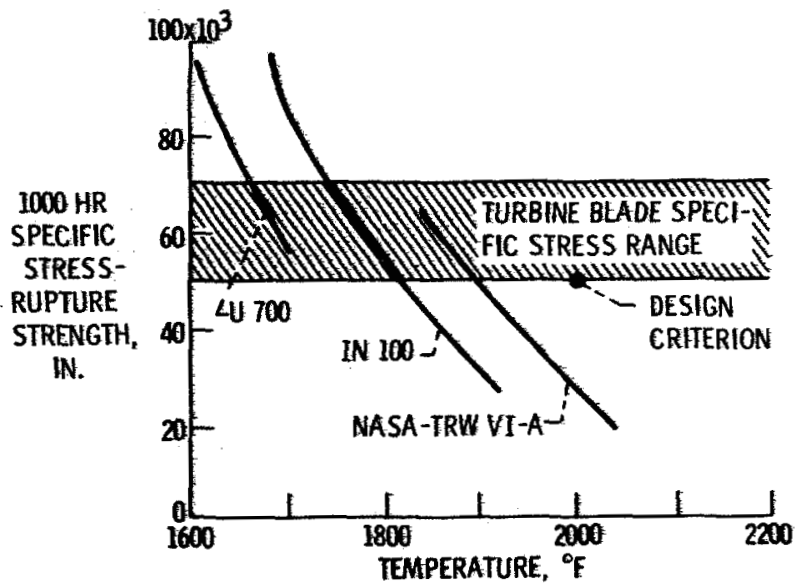

Figure 5. - Specific stress-rupture strengths of superalloys against temperature. The superimposed specific stress range is equivalent to that for nickel of cobatt base superalloys stressed between 15000 and 20000 psi. In addition, design criterion far calculated fiter strengths is indicated. 

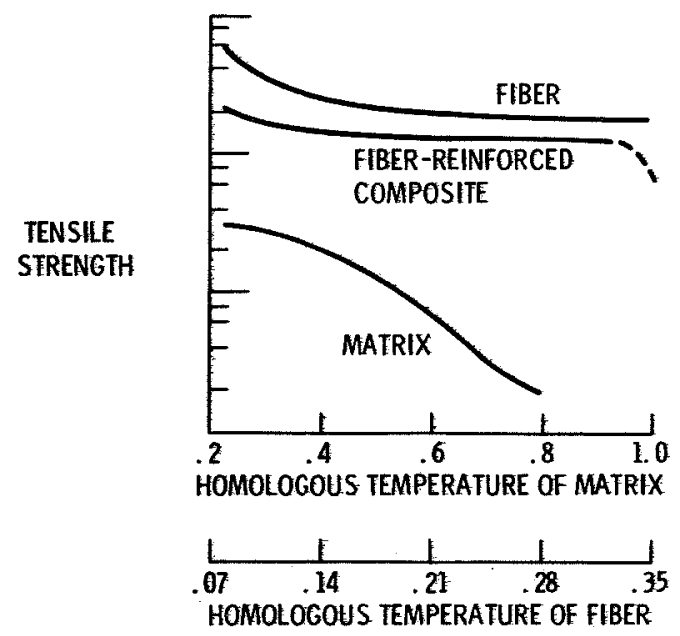

Figure 6. - Schematie comparison of tensile strength of composite and composite components as function of homologous temperature (ref. 4 ). 


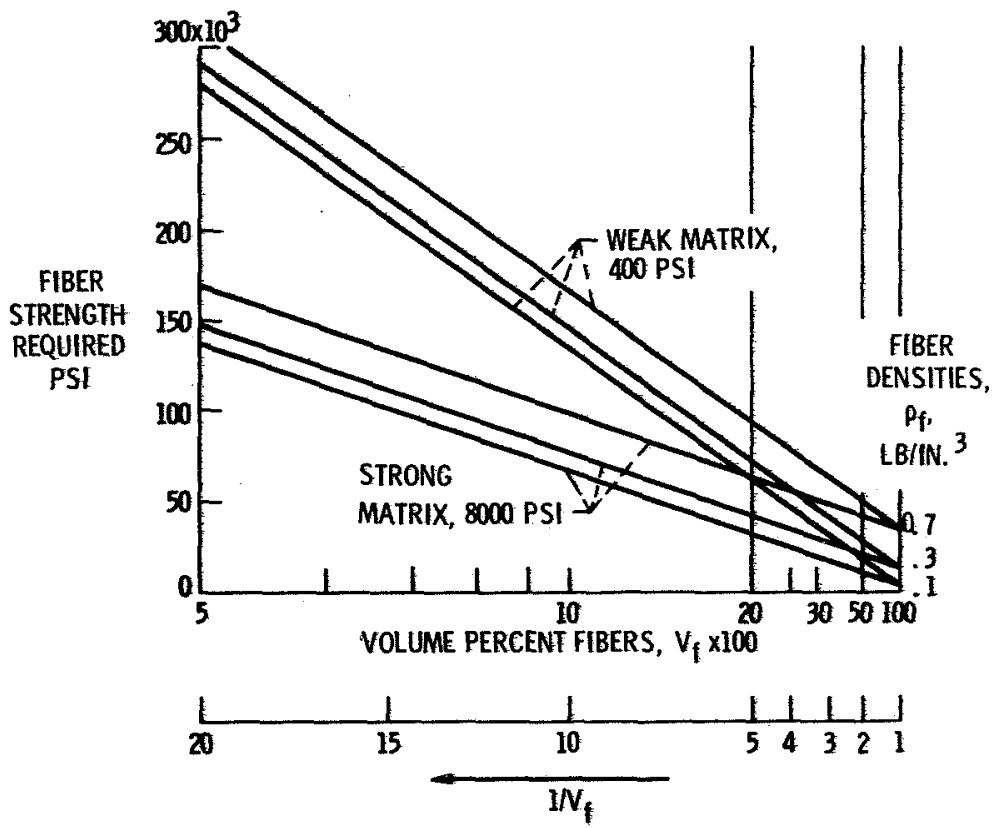

Figure 7. - Calculated fiber stress-rupture strengths required to produce high temperature composites suitable for gas tufbine blade use at $2000^{\circ} \mathrm{F}$. A specific stress-rupture strength of 50000 inches for 1000 hours at $2000^{\circ} F$ is the criterion used for the calculations. 


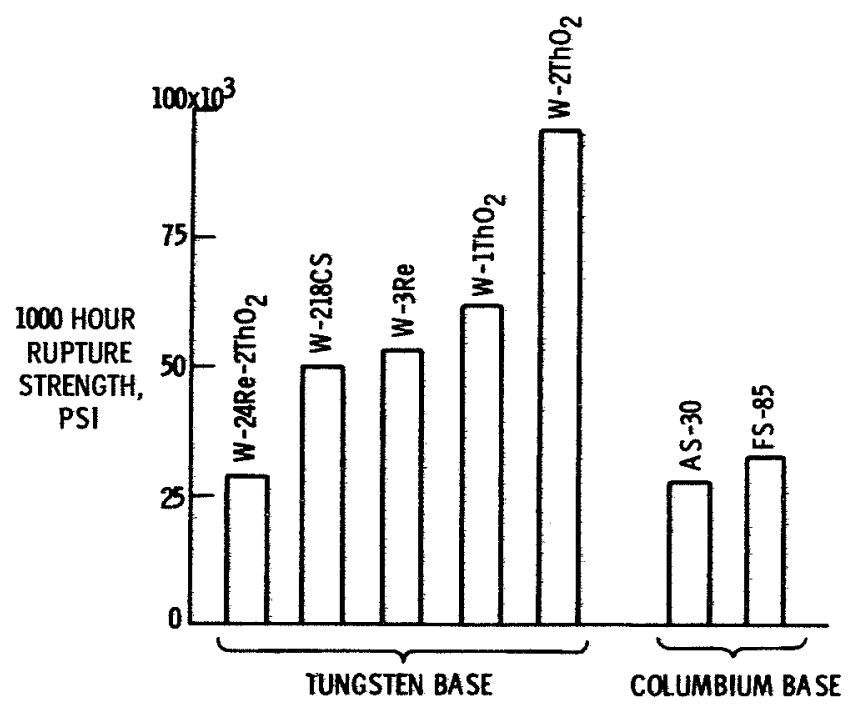

Figure 8. - Stress-rupture strengths of refractory metal wires for 1000 hours (ref. 15). 